\title{
Retrotransposon-based markers revealed a repartition depending on geographical origin and breeding status of Tunisian pistachio species
}

\author{
Khaled Chatti ${ }^{1 *}$, Sarra Choulak1', Soumaya Rhouma ${ }^{1}$, Karim Guenni ${ }^{2}$, Amel Salhi-Hannachi and \\ Noureddine Chatti ${ }^{1}$
}

\begin{abstract}
${ }^{1}$ Laboratory of Genetics, Biodiversity and Bioresources Valorisation (LR11ES41), Higher Institute of Biotechnology, University of Monastir, Monastir 5000, Tunisia

${ }^{2}$ Laboratory of Molecular Genetics, Immunology and Biotechnology, Faculty of Sciences of Tunis, Campus University, 2092 El Manar, Tunis, Tunisia
\end{abstract}

* Corresponding author: Khaled Chatti e-mail: ckhaled2000@yahoo.fr

\begin{abstract}
Retrotransposon movements are considered to be an important factor in evolutionary processes and speciation as well as a source of genetic variation. In order to analyze genetic diversity and population structure in Tunisian pistachio species, nine inter-retrotransposon amplified polymorphism (IRAP) markers were used. As a result, eighty-six amplicons were produced among which $98.15 \%$ were polymorphic. Mean numbers of the effective number of alleles (Ne), Shannon's information index $(\mathrm{I})$ and Nei's genetic diversity $(\mathrm{H})$ were respectively $1.529,0.478$, and 0.310 . The average within-population genetic diversity $(\mathrm{Hs})$ was 0.24 and the total diversity $(\mathrm{Ht})$ was 0.3 . The Tunisian pistachio populations exhibited high genetic differentiation (Gst $=0.275)$ and gene flow $(\mathrm{Nm}=1.888)$. The Analysis of Molecular Variance (AMOVA) indicated that variation was very high within populations (83\%). Phylogenetic tree using neighbor-joining (NJ) method and Principal Coordinates Analysis (PCOA) depicted that groupings of Tunisian varieties were made independently of the sex of the trees, but depending on their geographical origin and their breeding status. The modelbased Bayesian clustering (STRUCTURE) confirmed these observations. The inter-retrotransposons amplification polymorphism markers were significantly informative at the interspecific level. Findings reported in our study will be essential toward breeding for new pistachio genotypes with developed chemical and horticultural features.
\end{abstract}

Keywords: Pistacia; Retrotransposon; population structure; gene flow; plant breeding

\section{Introduction}

Over time, humans have domesticated plant and animal species to satisfy their needs. This practice has led to a progressive transformation both of them and their landscape (Zeder et al., 2006). The earliest agricultural civilizations were based mainly on cereal crops, which first appeared in the Middle East, and were quickly extended to West Asia, Egypt and Europe (Wadley and Martin, 1993). The cultivation of fruit trees seems to have started three thousand years later, again in the Middle East, and vegetable crops have followed later (Zohary et al., 2012). Since then, Mankind showed a real fascination with fruit trees. Tree species producing organoleptic and nutritional fruits have always been an interesting subject in research and human culture.

Because of its localization on the Mediterranean coast, Tunisia is a shelter for a wealth of plant and animal resources. In particular, crops that are bred in Tunisia adapt to a wide range of environments. There is extensive dryland agriculture where drought and heat are often severe and numerous biotic stresses affect the wide range of crops grown. Among the local plant biodiversity, fruit species occupy a strategic position given their environmental, agricultural and socio-economic roles. These fruit trees, which have an important adaptive capacity, are not very demanding on planting and produce fruits that are highly appreciated by consumers. As a result, these species have recently experienced renewed interest from farmers, breeders, researchers, and consumers.

Pistachio (Pistacia vera L. $2 n=30$ ) is a small fruit species that belongs to the Anacardiaceae family. It is the only 
cultivated and commercialized species in the genus Pistacia (Zohary, 1996). Indeed, four species belonging to the genus Pistacia are existing in Tunisia: Pistacia atlantica (Battoum) which is commonly used as a rootstock for vegetative propagation, Pistacia terebinthus, Pistacia lentiscus and Pistacia vera $\mathrm{L}$. The latter is native of arid and semi-arid zones and distributed throughout West Asia, the Middle East zones and the Mediterranean basin such as Greece, Italy, Spain, and Tunisia. The main $P$. vera nut-producing countries are Iran, USA, and Turkey. In Tunisia, the pistachio tree is an ancient crop, particularly in semi-arid and arid zones (Mlika, 1980). It is found in the north (Ariana, Jendouba, Bizerte and Le Kef), the center (Mahdia, Monastir, Kairouan, Kasserine and Sidi-Bouzid), and in the oases of southern Tunisia (Gafsa and El-Guetar). In this area, pistachio cultivation is an important economic activity as evidenced from the national production, which reached more than $3500 \mathrm{t}$ in 2017 making Tunisia rated amongst the top 10 countries in worldwide pistachio production (Faostat, 2017).

Despite the growing value of this fruit species, few studies have dealt with pistachio, especially with regard to the estimation of its genetic diversity and the analysis of population structure and domestication history. Among these few studies, Pazouki et al. (2010) used microsatellite markers for assessing genetic diversity and relationships among Pistacia species and cultivars. In 2006, Kafkas et al. detected DNA polymorphism and genetic diversity in a wide pistachio germplasm using different dominant molecular markers. More recently, Motalebipour et al. (2016), used SSR markers for genetic linkage map construction in pistachio.

In recent years and with the advent of next-generation sequencing (NGS) technologies, numerous whole genome sequence data from multiple species have become available, which offers a vast possibility for the enhancement of advanced markers in several plant species (Holland et al., 2001).In this context, numerous recent techniques for studying the genomic diversity of higher plants have been described. One of these is the IRAP "Inter-Retrotransposon Amplification Polymorphism" markers. It aims to detect the insertion polymorphism by amplifying a DNA segment comprised between two retrotransposons (Kalendar and Schulman, 2006). These retrotransposons are the most abundant transposable elements in many plant genomes (Kalendar et al., 2014). They have a "copy/paste" transposition mode involving an RNA medium and a reverse transcription process (Kalendar and Schulman, 2006). The transposition mechanism means that the insertions are irreversible and that the retro elements are able to be amplified into a very large number of copies (Mansour, 2008). These retro-elements are considered to be an important factor in evolutionary processes including speciation (Hamdi et al., 2000) as a source of genetic variation (Böhne et al., 2008). Retrotransposons can be applied as molecular markers because their incorporation makes new joints among genomic DNA and their conserved ends. Retrotransposons markers are detected by PCR, which amplifies a sequence of DNA at this joint (Kalendar and Schulman, 2006).This approach has been used to analyze diversity, similarity and genetic relationships in several plants such as rice (Oryza sativa L.) (Branco et al., 2007), flax
(Linum usitatissimum L.) (Smýkal et al., 2011), plum (Senkova et al., 2013), rye (Secalecereale L.) (Acherm et al., 2014) sorghum (Sorghum halepense L.) (Karimi and Saeidi, 2016) and table grapes (Strioto et al., 2019).

Our aim in the present study was to analyze the genetic diversity of pistachio in three Tunisian sites (El-Guetar, Gafsa and Sidi-Bouzid). The main objectives were the estimation of the extent of the molecular diversity, the establishment of phylogenetic relationships between accessions and the genetic structure of the studied populations. Results could be valuable for Tunisian Pistacia germplasm collection, conservation, and breeding

\section{Materials and Methods}

\section{Plant Materials}

Field visits were carried out in the central southern (Gafsa and El-Guetar oasis) traditional areas of pistachio growing in Tunisia. We also included accessions maintained at the Regional Center for Agricultural Research of Sidi-Bouzid (fig S1). Fortytwo Tunisian pistachio accessions (20 from El-Guetar, 6 from Sidi-Bouzid and 16 from Gafsa) including 30 female trees, nine male trees ( $P$. vera) and three $P$. atlantica were used in the study (Table 1). Plant material comprised fresh leaves of each adult tree. Samples were frozen at $-80^{\circ} \mathrm{C}$ awaiting their use for DNA purification.

\section{$D N A$ Isolation and PCR amplification}

DNA isolation is a crucial step for further DNA processing. Total genomic DNA was extracted from frozen leaves of single adult trees by means of a modified MATAB method (Risterucci et al., 2000). The present study consists in detecting the inter-retro transposable region; for this reason, the amplification has been carried out via universal LTR (Long Terminal Repeat) primers described by Smýkal et al. (2011) (Table 2). This method requires detecting the insertion polymorphism by amplifying the DNA fragment amongst two retrotransposons (Kalendar and Schulman, 2006) using a single primer complementary to a conserved LTR segment within a family.

Amplification was carried out in $25 \mu \mathrm{L}$ Reaction Mix con-

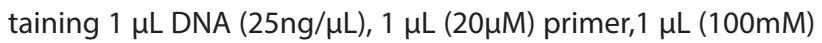
dNTP mix, 1 unit of Taq polymerase, and sterile $\mathrm{ddH}_{2} \mathrm{O}$. PCR amplification was realized according to the conditions described by Jiang et al. (2014). PCR results were observed by $1.5 \%$ agarose gel containing $0.5 \mu \mathrm{g} / \mathrm{mL}$ of ethidium bromide. Electrophoresis was performed in 1XTBE buffer solution at $5 \mathrm{~V} /$ $\mathrm{cm}$. Agarose gel was visualized and photographed under a Compact Digimage System, UVDI series (Major Sciences, USA).

\section{Statistical Analysis}

Amplicons generated by the IRAP technique were analyzed and each amplified DNA fragment treated as a di-allelic locus, 1 for presence and 0 for absence. Only polymorphic loci were considered during this analysis. Then, the data set was transformed into a binary matrix used to perform the statistical 
Table 1

Label, sex and origin of Tunisian pistachio cultivars studied.

\begin{tabular}{|c|c|c|c|c|c|}
\hline Geographic origin & Number & Labels & Sex & Species & Plant nature \\
\hline & 01 & GT1 & 운 & P. vera & Grafted plant \\
\hline & 02 & GT2 & 우 & P. vera & Grafted plant \\
\hline & 03 & GT3 & $\hat{0}$ & P. vera & Grafted plant \\
\hline & 04 & GT4 & 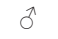 & P. vera & Grafted plant \\
\hline & 05 & GT5 & q & P. vera & Grafted plant \\
\hline & 06 & GT6 & $\hat{o}$ & P. vera & Grafted plant \\
\hline & 07 & GT7 & 우 & P. vera & Grafted plant \\
\hline & 08 & GT8 & 우 & P. vera & Grafted plant \\
\hline & 09 & GT9 & $\hat{0}$ & P. vera & Grafted plant \\
\hline \multirow[t]{13}{*}{ El Guetar (Tunisia) } & 10 & GT10 & 우 & P. vera & Grafted plant \\
\hline & 11 & GT11 & 우 & P. vera & Grafted plant \\
\hline & 12 & GT12 & q & P. vera & Grafted plant \\
\hline & 13 & GT13 & 우 & P. vera & Grafted plant \\
\hline & 14 & GT14 & 우 & P. vera & Grafted plant \\
\hline & 15 & GT15 & $\hat{0}$ & P. vera & Grafted plant \\
\hline & 16 & GT16 & q & P. vera & Grafted plant \\
\hline & 17 & GT17 & 우 & P. vera & Grafted plant \\
\hline & 18 & GT18 & 우 & P. vera & Grafted plant \\
\hline & 19 & GT19 & q & P. vera & Grafted plant \\
\hline & 20 & GT20 & 우 & P. vera & Grafted plant \\
\hline & 21 & GF1 & $\hat{\sigma}$ & P. vera & Grafted plant \\
\hline & 22 & GF2 & $\hat{0}$ & P. vera & Grafted plant \\
\hline \multirow[t]{10}{*}{ Gafsa (Tunisia) } & 23 & GF3 & 우 & P. vera & Grafted plant \\
\hline & 24 & GF4 & 우 & P. vera & Grafted plant \\
\hline & 25 & GF15 & 우 & P. vera & Grafted plant \\
\hline & 26 & Battoum 1 & & P. atlantica & wild seedling \\
\hline & 27 & SB1 & 우 & P. vera & Grafted plant \\
\hline & 28 & SB2 & q & P. vera & Grafted plant \\
\hline & 29 & SB3 & 우 & P. vera & Grafted plant \\
\hline & 30 & SB4 & 우 & P. vera & Grafted plant \\
\hline & 31 & SB5 & $\hat{0}$ & P. vera & Grafted plant \\
\hline & 32 & SB6 & $\hat{0}$ & P. vera & Grafted plant \\
\hline \multirow[t]{10}{*}{ Sidi Bouzid (Tunisia) } & 33 & SB7 & 우 & P. vera & Grafted plant \\
\hline & 34 & SB8 & 우 & P. vera & Grafted plant \\
\hline & 35 & SB9 & 우 & P. vera & Grafted plant \\
\hline & 36 & SB10 & 우 & P. vera & Grafted plant \\
\hline & 37 & SB11 & 우 & P. vera & Grafted plant \\
\hline & 38 & Matteur1 & q & P. vera & Grafted plant \\
\hline & 39 & Matteur2 & 우 & P. vera & Grafted plant \\
\hline & 40 & Irani & 우 & P. vera & Grafted plant \\
\hline & 41 & Battoum2 & & P. atlantica & wild seedling \\
\hline & 42 & Battoum3 & & P. atlantica & wild seedling \\
\hline
\end{tabular}

analyses. Accordingly, to estimate the efficiency of the primers used, some parameters have been calculated such as Polymorphic bands (PB), percentage of polymorphic bands (PPB), Polymorphic information content (PIC) (Ghislain et al., 1999) and the resolving power of the primer (Rp) (Prevost and Wilkinson 1999). In addition, genetic diversity measures $(H$, total gene diversity; $H_{s^{\prime}}$ mean genetic diversity within the population; $\mathrm{G}_{s t^{\prime}}$ the coefficient of gene differentiation; Ne: effective number of alleles) were tested using POPGENE (Yeh et al. 1999).

Genetic diversity measures for each population (NPB: number of polymorphic band; PPB: percentage of polymorphic bands; I: Shannon information index of diversity; $\mathrm{H}$ : Nei's genetic diversity and Na: observed number of alleles) were also assessed using POPGENE (Yeh et al. 1999). Furthermore, estimate of gene flow $\left(N_{m}\right)$ among populations was determined according to the formula $\mathrm{Nm}=0.25 \times\left(1-\mathrm{G}_{\mathrm{st}}\right) / \mathrm{G}_{\mathrm{st}}$ (McDermott and McDonald, 1993). Additionally, the Analysis of Molecular Variance (AMOVA) implemented in the GenAIEx 6.5 program (Peakall and Smouse 2006) was executed, based on 999 permutations, to screen the total IRAP variation within and among populations. 
Table 2

Genetic parameters of nine IRAP markers: TB: total number of bands; PB: polymorphic bands; PPB: percentage of polymorphic bands; PIC: Polymorphic information content; Rp: the resolving power of the primer. $H_{t}$ : total gene diversity; $H_{s}$ : mean genetic diversity within the population; $G_{s t}$ the coefficient of gene differentiation; Na: observed number of alleles; Ne: effective number of alleles; I: Shannon information index of diversity; $\mathrm{H}$ : Nei's genetic diversity.

\begin{tabular}{|c|c|c|c|c|c|c|c|c|c|c|c|c|c|}
\hline Locus & Sequences $\left(5^{\prime}-3^{\prime}\right)$ & TB & PB & PPB (\%) & PIC & $\mathrm{Rp}$ & $\mathrm{Ht}$ & $\mathrm{Hs}$ & Gst & $\mathrm{Na}$ & $\mathrm{Ne}$ & $\mathrm{H}$ & 1 \\
\hline LTR1 & ACCCCTTGAGCTAACTTTTGGGGTAAG & 13 & 13 & 100 & 0.422 & 0.422 & 0.256 & 0.218 & 0.990 & 2 & 1.428 & 0.272 & 0.428 \\
\hline LTR2 & CTTGCTGGAAAGTGTGTGAGAGG & 16 & 16 & 100 & 0.379 & 7.476 & 0.236 & 0.185 & 0.152 & 2 & 1.353 & 0.237 & 0.387 \\
\hline LTR3 & TGTTAATCGCGCTCGGGTGGGAGCA & 5 & 5 & 100 & 0.5 & 7.308 & 0.387 & 0.343 & 0.097 & 2 & 1.701 & 0.388 & 0.565 \\
\hline LTR4 & AGCCTGAAAGTGTTGGGTTGTCG & 6 & 5 & 83.33 & 0.495 & 3.571 & 0.189 & 0.126 & 0.302 & 2 & 1.411 & 0.23 & 0.347 \\
\hline LTR5 & CTGGCATTTCCATTGTCGTCGATGC & 7 & 7 & 100 & 0.483 & 1.809 & 0.418 & 0.305 & 0.245 & 2 & 1.823 & 0.427 & 0.605 \\
\hline LTR6 & GCATCAGCCTGGACCAGTCCTCGTCC & 15 & 15 & 100 & 0.385 & 4 & 0.224 & 0.194 & 0.112 & 2 & 1.357 & 0.237 & 0.385 \\
\hline LTR7 & CACTTCAAATTTTGGCAGCAGCGGATC & 6 & 6 & 100 & 0.466 & 7.142 & 0.326 & 0.243 & 0.196 & 2 & 1.539 & 0.333 & 0.508 \\
\hline LTR8 & TCGAGGTACACCTCGACTCAGG & 11 & 11 & 100 & 0.463 & 11.095 & 0.365 & 0.278 & 0.241 & 2 & 1.575 & 0.332 & 0.576 \\
\hline LTR9 & ATTCTCGTCCGCTGCGCCCCTACA & 7 & 7 & 100 & 0.487 & 5.904 & 0.314 & 0.268 & 0.139 & 2 & 1.574 & 0.332 & 0.498 \\
\hline Mean & - & 9.555 & 9.444 & 98.15 & 0.453 & 4.047 & 0.302 & 0.240 & 0.275 & 2 & 1.529 & 0.310 & 0.478 \\
\hline total & & 86 & 85 & - & - & 52.774 & - & - & - & - & - & - & - \\
\hline
\end{tabular}

\section{Genetic relationships}

Principal Coordinates Analysis (PCoA) was applied to the marker data by means of GenAIEx 6.502 program, to construct a bi-dimensional graphic representation of the genetic variability of accessions agreeing to their genetic origin. Based on the similarity index, the Genedist program (Version 3-5726, PHYLIP Software) (Felsenstein, 1995) was used to produce a genetic distance matrix on the basis of the formula of Nei and Li (1979). Thus, the obtained distance matrix was imported into the PHYLIP Software (Felsenstein, 1995) to build the dendrogram based on the Neighbor-Joining (NJ) method (Saitou and Nei, 1987). Tree View software (Page, 1996) was used to illustrate the phylogenetic dendrogram.

\section{Population structure}

For population structure analysis, Bayesian model-based clustering program STRUCTURE version 2.3.3 (Pritchard et al., 2000) was implemented to deduce the most relevant number of clusters $(k)$ to our analysis. The original data matrices were imported into the program and ten independent replicate runs for each $k$ value were performed. Therefore, a possible number of genetic groups ( $k$ ) in our sample set was investigated by Structure Harvester 0.694 (a web-based program) for collating results produced by the STRUCTURE program, which summarized the results of repeated runs and given the optimal $K$ value using the Evanno method (Evanno et al. 2005). In fact, Structure Harvester 0.694 (Dent 2014: web version) provided a fast way to estimate log-likelihood of $k$ to choose the optimal $k$ value (corresponding to the number of genetic groups that best fit the data).

\section{Results}

\section{Polymorphisms of IRAP Markers and genetic diversity analysis}

A total of 86 identifiable amplicons were generated using nine prescreened IRAP primer sets. The number of amplicons varied from 5 (LTR3) to 16 (LTR2) per primer, corresponding to an average of 9.5 amplicons. The percentage of polymorphic bands (PPB) was $100 \%$ for all used primers with the exception of LTR4 whose percentage was 83.33 (Table 2).This result highlights a high degree of genetic diversity within the studied Tunisian pistachios. On the other hand, for every locus, the polymorphic information content was calculated. Values ranged from 0.379 (LTR2) to 0.5 (LTR3) (Table 2).The resolving power (Rp) of the tested primers ranged from 0.422 (LTR1) to 11.095 (LTR8). This result disclosed the efficiency of the primers used to detect diversity at DNA level. Based on the studied IRAP markers, $H_{\mathrm{s}}$ and $H_{\mathrm{t}}$ were calculated for all examined loci. The average within-population genetic diversity $\left(H_{\mathrm{s}}\right)$ was 0.24 and the total diversity $\left(H_{\mathrm{t}}\right)$ was 0.3 .Nei's $G_{s t}$ is generally used for describing the average amount of differentiation observed over multiple loci, the multi-locus values of $G_{\text {st }}$ were equal to 0.275 . On the other hand, the mean effective number of alleles $(\mathrm{Ne})$, Shannon's information index (I) and Nei's genetic diversity $(\mathrm{H})$ were equal to $1.529,0.478$, and 0.310 , respectively (Table 2 ).

The assessment of the genetic variation within different geographic areas of pistachio showed an average observed number of alleles (Na), Shannon's information index (I) and Nei's genetic diversity $(H)$ equal to $1.732,0.35$, and 0.229 , respectively (Table 3 ). The population El-Guetar displayed higher values of I (0.421), H (0.274) and genetic polymorphism (PPB: $90.7 \%)$ than the other two populations. In contrast, the population of Gafsa exhibited lower genetic polymorphism (46.51), lower Shannon information index of diversity $(I=0.235)$ and lower Nei's genetic diversity $(H=1.465)$. The average IRAP polymorphism in Tunisian pistachio population was important (73.26\%). $N_{m}$ estimation was performed on the 86 obtained IRAP loci. The mean value of gene flow $\left(N_{m}\right)$ for all loci was estimated by the formula $0.25 \times\left(1-G_{S T}\right) / G_{S T}$ It is considered high since $N_{m}>1\left(N_{m}=1.888\right)$.

Moreover, AMOVA was performed to test the significance of the partitioning of genetic variance between and within populations. The result indicated that variation was very high 
Table 3.

Genetic Variation Statistics within different geographic region of Tunisian Pistachio revealed by IRAP markers NPB: number of polymorphic band; PPB: percentage of polymorphic bands; I: Shannon information index of diversity; H: Nei's genetic diversity; Na: observed number of alleles; $\mathrm{Nm}$ gene flow.

\begin{tabular}{lccccccc}
\hline Population & N & NPB & PPB (\%) & I & H & Na \\
\hline El-Guetar & 20 & 78 & 90.70 & 0.4213 & 0.2745 & 1.9070 \\
Gafsa & 06 & 40 & 46.51 & 0.2358 & 0.1556 & 1.4651 \\
Sidi-Bouzid & 16 & 71 & 82.56 & 0.3947 & 0.2570 & 1.8256 \\
Mean & & 63 & 73.26 & 0.3506 & 0.2290 & 1.7325 \\
\hline
\end{tabular}

Table 4

Analysis of molecular variance (AMOVA) of the pistachio accessions revealed by IRAP markers

\begin{tabular}{|c|c|c|c|c|c|c|}
\hline Source & $d f$ & SS & MS & Est. Var. & $\%$ & P-value* \\
\hline Among Pops & 2 & 99.209 & 49.604 & 2.829 & $17 \%$ & $\mathrm{p}<0.001$ \\
\hline Within Pops & 39 & 526.529 & 13.501 & 13.501 & $83 \%$ & $p<0.001$ \\
\hline Total & 41 & 625.738 & & 16.330 & $100 \%$ & $\mathrm{p}<0.001$ \\
\hline
\end{tabular}

df: Degree of freedom; P-value: probability of null hypothesis

*Significance tests after 1000 permutations

within the populations (83\%) but low (17\%) among them (Table 4).

\section{Genetic relationships}

To increase the cluster analysis information, a multivariate approach was used. Fig. 1 illustrates the distribution of the ecotypes according to the first two components (axes1 and 2). Outcomes showed that almost $37.29 \%$ of the total variability was described by the first three PCoA. Varieties were clustered in three different groups in PCoA plot: El-Guetar (pop1), Gafsa (pop2), and Sidi-Bouzid (pop3) (Fig. 1). This result is confirmed by the dispersion of cultivars exposed by the $N J$ tree (Fig. 2). In fact, the dendrogram classified the 42 studied accessions into three major clusters. The first one (I) contained all 'El-Guetar' genotypes (1-20). The second clade (II) represented all Gafsa accessions (21-25), and the third clade (III) grouped Sidi-Bouzid (27-37), 'Irani'(26), and 'Matteur' varieties (38, 39) (Fig. 2). Otherwise, phylogenetic tree with neighbor-joining $(N J)$ method depicted that groupings of Tunisian varieties were made independently of the sex of the trees, but depending on their geographical origin and their breeding status. Indeed, El-Guetar and Gafsa varieties were clearly separated from those from Sidi-Bouzid. Moreover, the three ecotypes of Pistacia atlantica were placed in a separate subgroup in the third clade (Fig. 2).

\section{Population structure}

Population structure of the 42 Tunisian pistachio accessions was surveyed under the Hardy-Weinberg Equilibrium assumption, using STRUCTURE V2.3.3 software. Via a model-based Bayesian clustering, the log likelihood between following $\mathrm{k}$ values $(\Delta \mathrm{K})$ exhibited a higher level of clustering at $\mathrm{k}=2$ for the considered pistachio accessions
(Fig. 3b). The Structure at $\mathrm{k}=2$ enabled differentiating two major clusters (Fig. 3a). Cluster 1: included accessions from Sidi-Bouzid and wild pistachio accessions (Battoum). Cluster 2 was made of accessions from El-Guetar and Gafsa. As it turned out from the clustering analysis, a clear differentiation based on the geographic origin arise. At $\mathrm{k}=3$ and $\mathrm{k}=4$, there was not a clear discrimination between cultivars, although we observed heterogeneity in groups.

\section{Discussion}

IRAPs have been widely used to study genetic variability, genetic relationships, and genetic material management (Techen et al., 2004). Retrotransposons are very abundant and scattered in the majority of plant genomes. The dispersal and ubiquity of these elements in plant genomes provide an extraordinary basis for improving molecular marker systems (Kalendar et al., 1999; Waugh et al. 1997). Geological, topological and climatic variability are presented as an important factor in plant biodiversity. Thanks to this variability, the Mediterranean region is considered one of the cradles of biodiversity in the world (Myers et al. 2000). Among the Mediterranean regions, Tunisia is a center of diversification of several agricultural species where there are several cultivated varieties that often bear the name of a locality or that of a farmer. This diversity is of interest for species such as apricot, almond, pomegranate, date palm, pistachio.

The pistachio tree is one of the ancient plant species cultivated. It is a tree of great interest because of its productivity, the nutritional quality of its fruits and its ability to adapt to arid 


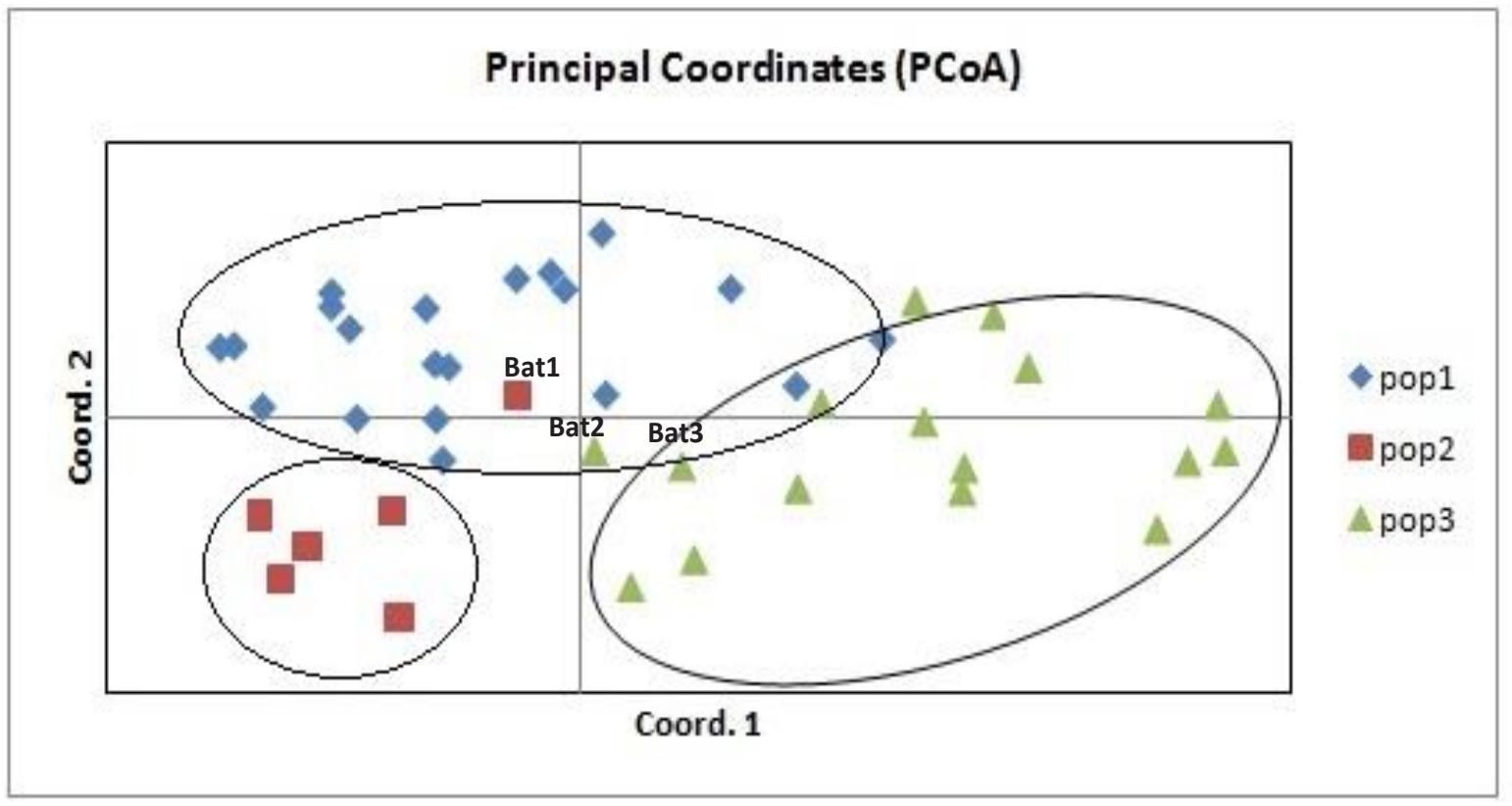

Fig 1

Principal coordinates analysis (PCoA) for the first and second coordinates estimated for IRAP markers (Axis 1 and 2 explain $30 \%$ of the total variability). Pop1=El-Guetar, Pop2=Gafsa and Pop3=Sidi-Bouzid.

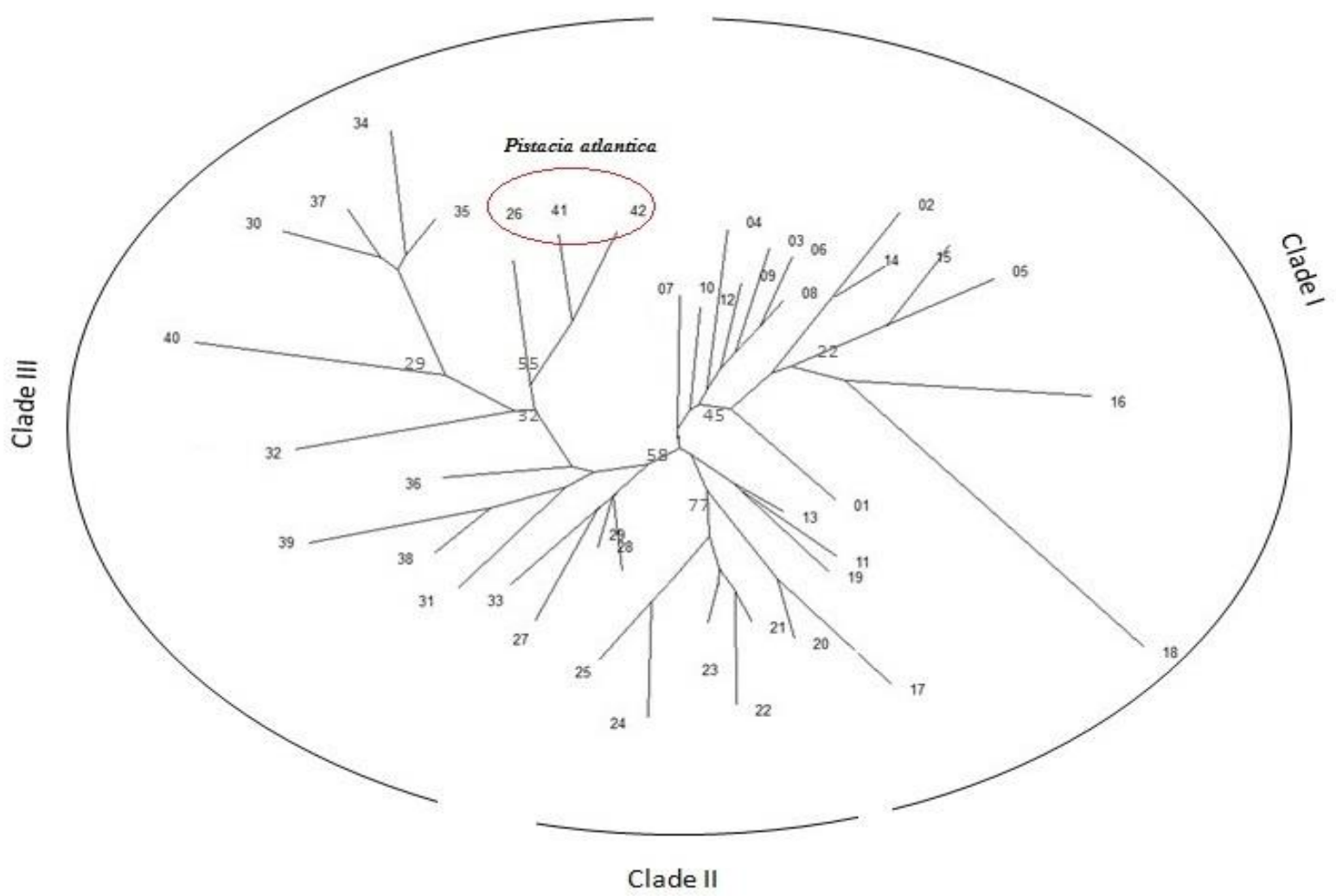

Fig 2

NJ dendrogram of Tunisian pistachio accessions constructed with Nei's genetic distances based on IRAP alleles. Clade I (El-Guetar), clade II (Gafsa) and clade III (Sidi-Bouzid). 

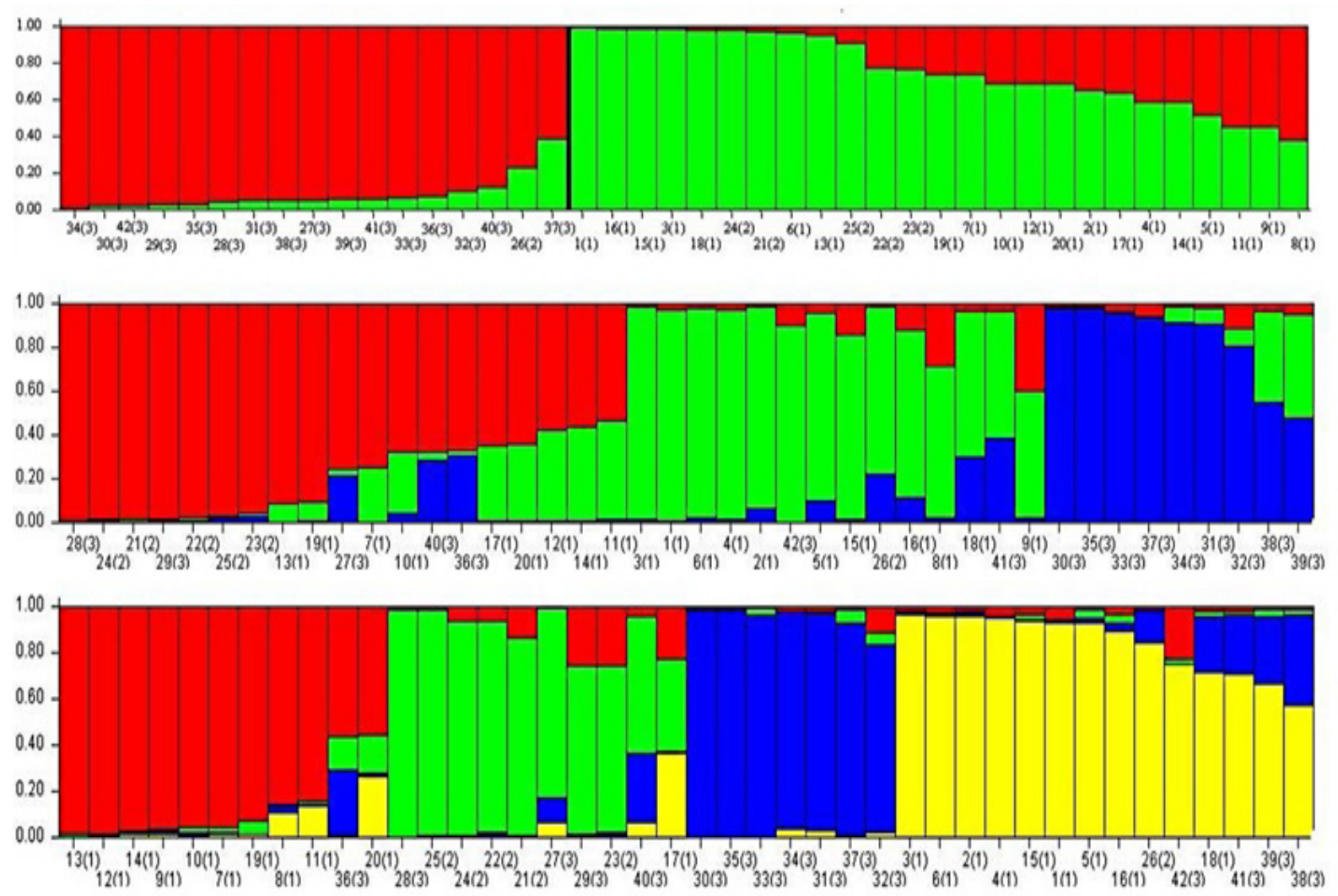

A

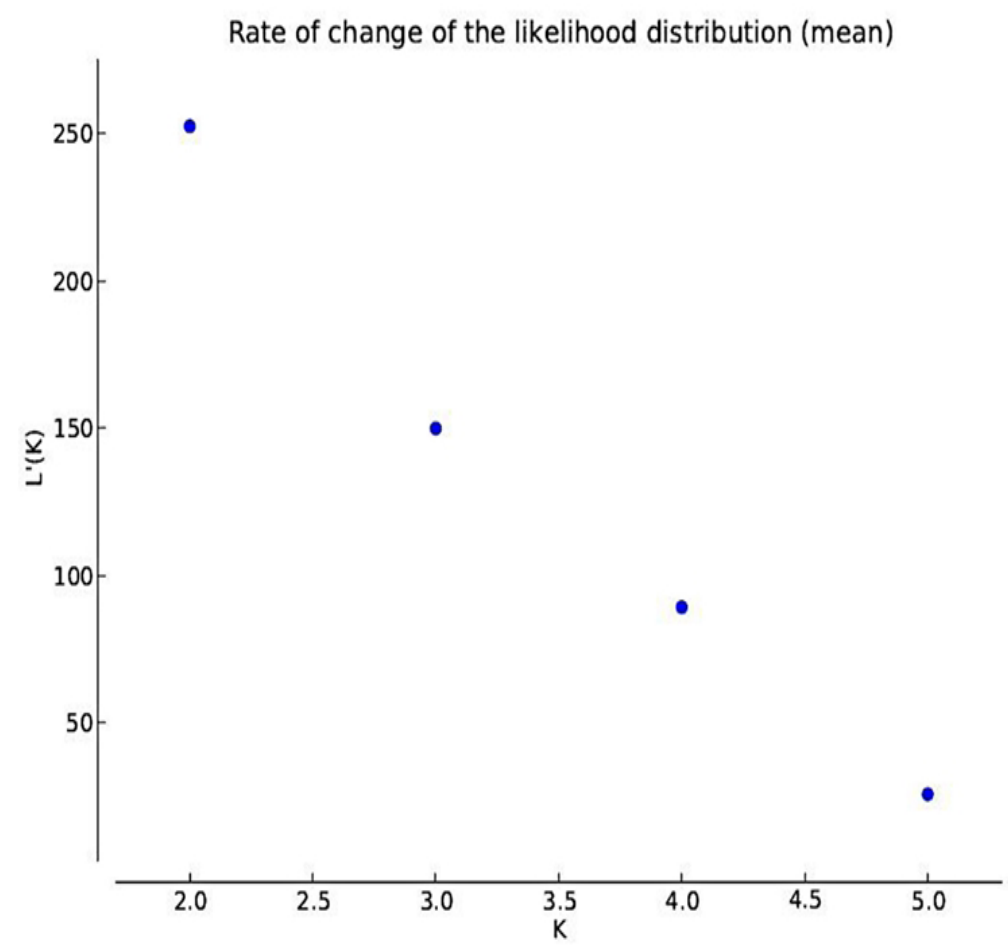

B

Fig.3

Estimated population structure based in IRAP markers using STRUCTURE software. a: Population structure, each color indicates a Group with the same genetic background. Bold lines represent the limit of the two genetic groups. b: Mean log likelihood Ln $\mathrm{P}(\mathrm{X} \mid \mathrm{K})$ as a function of the number of genetic clusters (K), in our case $\mathrm{K}=2$. Geographic origin: (1) El-Guetar, (2) Gafsa \& (3) SidiBouzid. 
and semi-arid regions. Like the Maghreb countries, Tunisian pistachio trees are constantly threatened by various abiotic and biotic stresses that have far-reaching environmental and socioeconomic impacts.

The main reason for exploring the genetics of $P$. vera $L$. in this study was to document conclusively the strong intra-specific variation in Tunisia, there was not enough data on this subject. In addition, our previous study (Chatti et al. 2017), in which we used morphological parameters, did not give clear results regarding the genetic organization of the Tunisian pistachio tree. The present study revealed a remarkably high level of genetic diversity in $P$. vera species based on IRAP markers. A total of 86 bands and 85 polymorphic bands with $98.15 \%$ of polymorphism were detected in this species. This result shows clearly the abundance of IRAP amplification bands, which indicates the large-scale dispersion of retrotransposons in the genome. Moreover, Nei's gene diversity index $(\mathrm{H})$ values within populations varied from 0.23 to 0.427 with an average of 0.31 . Our study clearly reveals that there is wide genetic variability among Tunisian $P$. vera germplasm. In fact, all tested primers are efficient to detect DNA polymorphisms in pistachio germplasm. This hypothesis is strongly supported in view of the high resolving power $(\mathrm{Rp}=52.774)$ and $\mathrm{PIC}(0.453)$ rates. Clustering and structure analysis based on IRAP markers indicated that Sidi-Bouzid population is most divergent from the other populations. The reason for this divergence can be its geographical background; the plant material was collected from the experimental orchard situated in the experimental station of the Agriculture Research Center (CRRA, Sidi-Bouzid). The growing region is characterized by a steppe Mediterranean type of weather with an annual rainfall of $200 \mathrm{~mm}$ and a reference evapo-transpiration of more than $1300 \mathrm{~mm}$. The soil is heavy and calcareous and has a clay-sandy texture (Abidi, 2016). While the oasis of El-Guetar has a very old irrigation system flowing from the bottom of the Orbata Mountains. The pistachio tree, adapted to the environment of the region, is the symbol of the city. Wild originally, it has been growing for thousands of years in Jebel Orbata. Thanks to Chott El-Guetar that has an area of 3730 ha, El-Guetar pistachios are closely associated with specific geological, geomorphological, and pedological features (Hachicha and Ben Aissa, 2014). The Chott acts as an evaporative system of various salts. These natural conditions give El-Guetar pistachios a special taste that distinguishes them from other regions. On the other hand, the mean value of gene flow $\left(N_{m}\right)$ for all loci was very high since $N_{m}>1\left(N_{m}=1.888\right)$. Gene flow is a process occurring both in time and in space, across pollen and seeds, which is strongly related to the horticultural system (Hamrick et al., 1993). In pistachio, as angiosperm species, plastids are exclusively inherited maternally. Thus, plastid population genetic structure should be determined by gene flow from seeds (Ellstrand, 2014). In Tunisia, seeds are rarely exchanged among regions of pistachio cultivation. The vegetative propagation is widely used (Maggs, 1973). Therefore, between these locations, female varieties are exchanged in order to provide a warranty for production in unfavorable growing areas.

\section{Conclusion}

In conclusion, it is crucial to figure out the genetic polymorphism and variation among and within accessions to adopt the efficient plan for conservation and sampling management. In this study, IRAP marker, in theory comparable to the ISSR and RAPD marker, was an efficient system to assess genetic variation and to detect polymorphism among $P$. vera accessions. The study of IRAP profiles of 42 accessions showed a wide genetic diversity in the Tunisian Pistachio germplasm and a clear pattern of genetic variability could be elucidated between populations. This novel information is very essential for opening extensive horizons for growing new cultivars with developed chemical and horticultural features. In addition, our findings will be an important resource for the study of sex determinism, seed propagation and controlled crosses.

\section{Acknowledgements}

This work was supported by grants from the Tunisian Ministry of Higher Education and Scientific Research. The paper is dedicated to the late Professor Imen Said.

\section{References}

Abidi W (2016) Pomological and physical attributes of pistachio (Pistacia vera L.) varieties grown in west-central Tunisia. Journal of new sciences, Agriculture and Biotechnology 28(4), 1582-1588

Achrem M, Kalinka A, Rogalska SM (2014) Assessment of genetic relationships among Secale taxa by using ISSR and IRAP markers and the chromosomal distribution of the AAC microsatellite sequence. Turkish Journal of Botany 38(2), 213-225. https://doi:10.3906/bot-1207-1226

Böhne A, Brunet F, Galiana-Arnoux D, Schultheis C, Volff JN (2008) Transposable elements as drivers of genomic and biological diversity in vertebrates. Chromosome research. 16(1), 203-215 https://doi.org/10.1007/s10577-007-1202-6

Branco CJS, Vieira EA, Malone G, et al. (2007) IRAP and REMAP assessments of genetic similarity in Rice (Oryza sativa). Journal of Applied Genetics 48(2), 107-113. https://doi.org/10.1007/BF03194667

Chatti K, Choulak S, Guenni K, Salhi-Hannachi A (2017) Genetic diversity analysis using morphological parameters in Tunisian Pistachio (Pistacia vera L.). Journal of Research in Biology Sciences, 02: 29-34

Dent EA (2014) STRUCTURE HARVESTER version 0.694. http://tayloro.biology.ucla.edu/structureHarvester/.

Ellstrand NC (2014) Is gene flow the most important evolutionary force in plants? Am. J. Bot. 101(5), 737-753. https://doi.org/10.3732/ajb.1400024

Evanno G, Regnaut S, Goudet J (2005) Detecting the number of clusters of individuals using the software STRUCTURE: a simulation study. Mol. Ecol.14, 2611-2620. https://doi.org/10.1111/j.1365-294x.2005.02553.x

Faostat (2017) http://www.fao.org/faostat/en/data/QC

Felsenstein J (1995) PHYLIP (Phylogeny Interference Package) version 3,5 c. Department of Genetics, University of Washington, Seattle, Washington

Ghislain M, Zhang DP, Fajardo D, Huamán Z, Hijmans RJ (1999) Marker-assisted sampling of the cultivated Andean potato Solanumphureja collection using RAPD markers. Genetic Resources and Crop Evolution 46, 547-555. https://doi.org/10.1023/A:1008724007888 
Hachicha M, Ben Aissa I (2014) Managing salinity in Tunisian oases. Life Sciences Journal 8(9), 775-782. https://doi.org/10.17265/1934-7391/2014.09.007

Hamdi HK, Nishio H, Tavis J, Zielinski R, Dugaiczyk A (2000) Alu-mediated phylogenetic novelties in gene regulation and development. Journal of Molecular Biology 299(4), 931-939. https://doi.org/10.1006/jmbi.2000.3795

Hamrick JL, Murawski DA, Nason JD (1993) The influence of seed dispersal mechanisms on the genetic structure of tropical tree populations. Vegetation 107(1), 281-297. https://doi.org/10.1007/BF00052230

Holland JB (2001) Epistasis and plant breeding. Plant Breeding. Reviews. 21 2792. https://doi.org/10.1002/9780470650196.ch2

Jiang LF, Qi X, Zhang XQ, Huang LK, Ma X, Xie WG (2014) Analysis of diversity and relationships among orchardgrass (Dactylis glomerata L.) accessions using start codon-targeted markers. Genetic Molecular. Research 13, (2): 4406 4418. https://doi.org/10.4238/2014.june.11.4

Kafkas S, Hakan O, Bekir E, Izzet A, Halit Seyfettin A, Sonay K (2006) Detecting DNA polymorphism and genetic diversity in a wide pistachio germplasm: Comparison of AFLP, ISSR, and RAPD markers." Journal of the American Society for Horticultural Science 131.4, 522-529. https://doi.org/10.21273/JASHS.131.4.522

Kalendar R, Grob T, Regina M, Suoniemi A, Schulman A (1999) IRAP and REMAP: two new retrotransposon-based DNA fingerprinting techniques. Theoretical and Applied Genetics 98: 704-711. https://doi.org/10.1007/s001220051124

Kalendar R and AH Schulman (2006) IRAP and REMAP for retrotransposon-based genotyping and fingerprinting. Nature Protocols. 1(5), 2478-2484. https://doi: 10.1038/nprot.2006.377

Kalendar R, Schulman AH (2014) Transposon-based tagging: IRAP, REMAP, and iPBS. Methods Molecular Biology (1115) 233-55. https://doi: 10.1007/978-1-62703-767-9 12

Karimi A, Saeidi H (2016) Genetic diversity of Sorghum halepense (L.) Pers. in Iran as revealed by IRAP markers. Plant. Genetic. Resources. 14(2), 132-141. https://doi.org/10.1017/S1479262115000167

Maggs DH (1973) Genetic resources in pistachio. Plant. Genet. Resources. Newsletter. 29: 7-15

Mansour A (2008) Utilization of genomic retrotransposons as cladistics markers. Journal of Cell and Molecular Biology: 7, 17-28

McDermott JM and BA McDonald (1993) Gene flow in plant pathosystems. Annual Review of Phytopathology: 31(1), 353-373

Mlika M (1980) Contribution à l'étude du pistachier en Tunisie : Choix de variétés mâles et femelles à floraison synchrone- Anatomie des fleurs. Mémoire de fin d'études du cycle de spécialisation INAT, Tunisie

Myers N, Mittermeier RA, Mittermeier CG, Da Fonseca GAB, Kent J (2000) Biodiversity hotspots for conservation priorities. Nature. 403(6772), 853-858. https://doi.org/10.1038/35002501

Nei M, Li WH (1979) Mathematical model for studying genetic variation in terms of restriction endonucleases. Proc. Natl. Acad. Sci. USA.76(10): 5269-5273. https://doi.org/10.1073/pnas.76.10.5269

Page RDM (1996) TREEVIEW: An application to display phylogenetic trees on personal computers. Comput. Appl. Biosci.12, 357-358. https://doi.org/10.1093/bioinformatics/12.4.357

Pazouki L, Mardi M, Shanjani PS, et al. (2010) Genetic diversity and relationships among Pistacia species and cultivars. Conservation Genetics 11, 311-318. https://doi.org/10.1007/s10592-009-9812-5

Peakall R, Smouse PE (2006) GENALEX 6: genetic analysis in Excel. Population genetic software for teaching and research. Molecular Ecology Notes.6, 288-295. https://doi.org/10.1111/j.1471-8286.2005.01155.x

Prevost A, Wilkinson M (1999) A new system of comparing PCR primers applied to ISSR fingerprinting of potato cultivars. Theoretical and Applied Genetics 98, 107-112. https://doi.org/10.1007/s001220051046

Pritchard JK, Stephens M, Donnelly P (2000) Inference of population structure using multilocus genotype data. Genetics.155, 945-959

Risterucci AM, Grivet L, N'goran J, Pieretti I, Flament MH, Lanaud C (2000) A high-density linkage map of Theobroma cacao L. Theoretical and Applied Genetics 101(5), 948-955. https://doi.org/10.1007/s001220051566

Saitou N, Nei M (1987) The neighbor-joining method: a new method for reconstructing phylogenetic trees. Molecular Biology Evolution 4(4), 406-425. https://doi.org/10.1093/oxfordjournals.molbev.a040454

Senkova S, Ziarovska J, Bezo M (2013) Utilization of IRAP technique for plums genotypes differentiation. Biosci. Res. 10(1), 01-07
Smykal P, Bacova-Kerteszova N, Kalendar R, Corander J, Schulman AH, Pavelek M (2011) Genetic diversity of cultivated flax (Linum usitatissimum L.) germplasm assessed by retrotransposon-based markers. Theoretical and Applied Genetics 122(7), 1385-1397. https://doi.org/10.1007/s00122-011-1539-2

Strioto D, Kuhn B, Nagata W, Marinelli G, Oliveira-Collet S, Mangolin C, Machado M (2019) Development and use of retrotransposons-based markers (IRAP/ REMAP) to assess genetic divergence among table grape cultivars. Plant Genetic Resources: Characterization and Utilization. 17(3), 272-279. https:// doi:10.1017/S1479262119000029

Techen N, Crockett SL, Khan IA, Scheffler BE (2004) Authentication of medicinal plants using molecular biology techniques to compliment conventional methods. Current Medicinal Chemistry 11(11), 1391-1401. https://doi.org/10.2174/0929867043365206

Wadley G, Martin A (1993) The origins of agriculture: a biological perspective and a new hypothesis. Australian Biologist 6, 96-105

Waugh R, McLean K, Flavell AJ, Pearce SR, Kumar A, Thomas BBT, Powell W (1997) Genetic distribution of BARE-1-like retrotransposable elements in the barley genome revealed by sequence-specific amplification polymorphisms (S-SAP). Molecular and General Genetics 253, 687-694. https://doi.org/10.1007/s004380050372

Yeh F, Yang R, Boyle T (1999) POPGENE Version 1.31, Microsoft Windows-Based Freeware for Population Genetic Analysis. Quick User Guide; University of Alberta. Edmonton, $A B$, Canada

Zeder MA, Emshwiller E, Smith BD, Bradley DG (2006) Documenting domestication: the intersection of genetics and archaeology. Trends in Genetics 22, 139-55. https://doi.org/10.1016/j.tig.2006.01.007

Zohary D (1996) The genus Pistacia L. In Taxonomy, distribution, conservation and uses of Pistacia genetic resources, Padulosi S, Caruso T, Barone E (eds) (IPGRI, Palermo), pp. 1-11

Zohary D, Hopf M, Weiss E (2012) Domestication of Plants in the Old World. The origin and spread of domesticated plants in Southwest Asia, Europe, and the Mediterranean Basin. Oxford University Press, UK. 264p. https://doi.org/10.1093/acprof:osobl/9780199549061.001.0001

Ziya Motalebipour E, Kafkas S, Khodaeiaminjan M, et al. (2016) Genome survey of pistachio (Pistacia vera L.) by next generation sequencing: Development of novel SSR markers and genetic diversity in Pistacia species. BMC Genomics 17, 998. https://doi.org/10.1186/s12864-016-3359-x 